\title{
Reimagining Crises in the Indian University
}

\section{Shreya Urvashi ${ }^{1}$ (D)}

Received: 20 July 2020 / Revised: 27 September 2020 / Accepted: 5 November 2020 /

Published online: 14 November 2020

C Springer Nature Switzerland AG 2020

\begin{abstract}
The public university in India was conceptualized to provide economically accessible and socially inclusive education. It has had the dual task of simultaneously critiquing and serving the nation. However, along with the declining quality of higher education, there has also been a significant decline in public funding recently. Increasing government intervention in the everyday life of university has further resulted in policies that inadvertently have much to do with increasing surveillance and regulation of university spaces. Placing this within the ambit of the national political situation, there was a lot of student activism and unrest on city streets and inside campuses. A global public health crisis in the midst of all this resulted in a tangential change from the above issues to those of infrastructure, access, and inclusion. At this juncture then, it becomes imperative to reevaluate the purpose of the existing institutions. The paper thus is an attempt to contextualize contemporary Indian higher education, in times of the pandemic. A qualitative approach using unstructured (physical and virtual) conversations along with literature survey has been used. An analysis of the factors, like research quality, institutionalized discrimination, infrastructure, and public funding, is used to decipher how the public university in India negotiates and exists as a prominent social institution in the country.
\end{abstract}

Keywords Higher education · Crisis · India · Student activism · Access · Quality

\section{Introduction}

Universities are free spaces. They can be considered as a catalyst of scientific and economic change, as well as a medium of equalization of chances and democratization of society by making possible equal opportunities for people-contributing not only to economic growth but also to social equality or, at least, lesser inequality. Writings of Beteille (2005), Viswanathan (2000), Misra (2018), and Guha (2007) reveal that education in a university should create a learning that cultivates universal values of equality, liberty, and fraternity for building a progressive nation-state. It should guide a progressive intellectual movement and cultivate the urge for social justice. However, a critical analysis of the intellectual and social history of a university reveals that it is a site of contestation between multiple

Shreya Urvashi

shreyaurvashi@gmail.com

1 Centre for Studies in Sociology of Education, Tata Institute of Social Sciences, Mumbai, India 
spaces and identities inherited and generated by the university itself (Gundemeda 2017). The social values and meanings attached to these spaces are highly conditioned by caste, class, gender, religious, regional, linguistic, and political ideologies of students. As a social institution, it is forced to engage with the broader social, political, and cultural encounters of its society.

In India, as in many other parts of the world, students in higher education constitute a minuscule numerical population that is considered an elite both in terms of intellect as well as the power to form or influence state decisions (Urvashi 2018). University education is especially important, as students in universities are comparatively older and influence society heavily by becoming agents of social change. In a developing society, the economy is changing in unprecedented and unpredictable ways. Thus, the economic and social toll of adjustments-high levels of employment, expansion of the service sector, intensified international trade competition, changing requirements within the occupation and related technological innovations - is high and shows no signs of reversal in the near future.

While it can be argued that India's universities have successfully provided valuable services to Indian society, namely social mobility and skilled workforce, most observers also agree that Indian universities need a major overhaul (Altbach 1974). There is a university crisis that can be substantiated from the various studies that report of disruption of academic life, dissatisfaction among students, the dismal state of the examination system, and shambling infrastructure as well as a structure that leads to unemployment. Governmentdesignated commissions have not been able to change much in the situation. Reforms have been constantly sought to improve aspects of the academic environment in the country.

Increased government intervention in everyday life of university has resulted in policy formulation that inadvertently has much to do with increasing surveillance and regulation of university spaces (Chandra 2017). There has moreover been a recent shift to prioritize research and teaching in relevant areas, which is bound to acutely affect some fields more than others. For instance, the humanities, with regard to teaching and research, have not been created for applied research, and tend to yield results slowly and indirectly. Subjects like sociology, literature and philosophy are also deeply political, and are frequently seen to be subversive to the establishment. Thus, the current state of higher education in India needs consistent comprehensive interrogation.

\section{The Evolution of Indian Universities}

Education, including higher and specialized education, has been a part of India since ancient times. There are a large number of texts and commentaries available in various disciplines, including philosophy, literature, Ayurveda, mathematics, agriculture, music, and sculpture, that provide evidence of a great tradition of rigorous indigenous scholarship. Further proofs are the remains of universities like those at Nalanda, Vikramshila, Odantapuri, and Taxila that, though different from today's universities in terms of aims, structures, and functioning, pursued a unique model Guru-Shishya (teacher-student) relationship (Misra, 2020).

The history of modern, and currently existing, university education began with the Universities of Calcutta, Madras and Bombay in 1857 (Gundemeda 2017). Post-graduate teaching and research departments began to be established around 1920. It was started by the British colonizers, with the goal of maintaining and nourishing their rule. It engaged the young elites with the Western knowledge system and helped produce a workforce that 
could serve as civil servants (Misra 2020). As a corollary thus, the preferred medium in these universities was English. This is not to say that there were no universities in any of the other Indian languages; instead only to emphasize the dominance of English-medium government-supported higher education. Thus, higher education exacerbated the pre-existing social inequalities by creating another level of inequality in the form of English education and Western knowledge.

After independence in 1947, however, the national leadership got the opportunity to reconstruct the education system. While pre-independence Indian Higher Education was searching for modernity under the colonial legacy, the first independent government attempted to correlate the education with the national goals of independent India. These national goals were imbibed in the Indian Constitution; and include Democracy, Secularism, elimination of poverty, to create a socialist society, and to create national integration (Naik 1965). As articulated by Rizvi (2012) the postcolonial aspirations of Indian society had to "embrace science and technology as the language of development and directed towards an emancipatory quest for a new social order free from hierarchical structures." The amalgamation of these aspirations required transforming an elite system to an egalitarian system Beteille, (2010).

There have been significant changes in the field of higher education during the last three decades. The phenomenal growth in the number of colleges and universities, the high enrolment and turnover of degree holders, the increase in the teacher salaries, the sixfold increase in the higher education budget provide some indicators of the progress made. On the other side of the balance sheet is the high percentage of drop out, the ever-growing educated unemployed, the drain of skilled workforce, and the continuing chorus of concern about the lowering standards of teaching. From this, one cannot escape the two apparent conclusions. The productive capacity of the system has gone up, but the relevance of the product has gone down. The teacher has been rehabilitated, but the degree has been devalued.

The traditional base of Indian higher education, the liberal-arts college, started waning in prestige and importance post-independence because the standards of instruction at those colleges began declining as the student population expanded at an unprecedented rate. The value of science education, on the other hand, increased substantially, as India's industrial production rose, and the standards of admission into the scientific fields tightened in order to protect standards of instruction. Technological institutions were created and given sufficient financial resources, while the liberal-arts colleges were allowed to expand almost without limit and were not adequately financed. Further, as the number of graduates of the liberal arts exceeded the number of jobs available, educated unemployment became an increasing problem, and holders of BA degrees could consider themselves fortunate in finding clerical employment. Many employers began to demand a college degree for positions previously filled by literate, but academically unqualified individuals.

Nevertheless, as the educational system grew, higher education became available to broader segments of the population, thereby destroying the homogeneity of the student population. Members of the student community had little in common since students were drawn from diverse class and caste backgrounds. Thus, gradually a kind of "dual culture" evolved on campus. Students from lower castes and classes, who also comprised a significant portion of first-generation learners, suffered most from the disadvantages of Indian higher education-poor conditions, and falling standards of instruction, crowded institutions, and fear of unemployment. It led to a defining structure of the education system. While working-class students or those from rural areas generally started going into liberalarts subjects; the upper- and middle-class students tended to go into the sciences. 
This has had significant implications for Indian higher education and for student political involvement. University students had been a massive force during the freedom struggle. While at that time, the goals were clear, students also had an ample number of nationalist leaders to follow. Post-independence, not only did the leadership decline, the abovementioned changing perceptions of higher education also played a role. Students in the natural sciences had traditionally been less concerned with politics and more professionally oriented than liberal-arts students, and the shifts meant that the "meritorious" students were no longer interested in political affairs. Students in the sciences often did not have time for political activity, since their academic programs were time-consuming and demanding. These changing conditions have altered the number and quality of students available for continuing political activity. Further, students from the lower middle- and working-class families were often unwilling to risk their college careers to participate in political activity, and, in any case, they lacked a tradition of political activism.

Today, Indian higher education is majorly dependent on state funding and is amongst the most important avenues of mobility for all classes, including the affluent class. That is why, unlike primary or secondary education, institutions of higher and specialized education are subject to enormous political and social pressure. When this translates into practice, many socio-political concerns come out. For instance, the appointment of faculty and intervention in the curriculum are predominantly influenced by the social, cultural, and political situation of the State. Further, the infamous caste system of India has also always found a way to determine the university in the country. The 1970s and 1980s were periods of turmoil on campuses which led to massive changes in university demography. Politically resurgent lower castes and classes are now challenging the longstanding monopoly of the upper-caste and upper-class elite over these resources (Deshpande 2009).

The present situation is wanting. Not only has there been a constant deterioration in the quality of higher education, there has been an effort to slowly restructure Indian higher education. This is apart from the significant decline in public funding, with the transformation of universities into cost-centers where the growth and survival of every centre are related to the funds it can manage. While on the one hand, about half of the posts of professors, readers, and lecturers are vacant across the country, on the other, nearly the same number of college teachers are temporary. Moreover, part-time and contractual teachers are often paid much lesser as compared to the amount of work that is required from them. Deficient infrastructure and poor libraries are other concerns. Hence, the crisis of the public university and the move towards privatization in India have taken a more definitive shape in the last few years.

\section{The Crises}

There is consensus that there exists a severe crisis in higher education. Newspaper reports frequently mention of leakage of examination papers, failure in examination conduction, dismal recruitment process, inhuman ragging at apex institutions, as well as student suicides. They also talk about protests and strikes by students, faculty and other employees for various issues. Further, faculty talk about frequent delays in payment of salaries, and the lack of opportunities and facilities for research. They are alienated from their work since they have no control, either over defining the syllabi they teach, or over the assessment of their students. Students, on the other hand, are dismayed about issues that include but go 
much beyond the uncertainty of admissions, the poor quality of teaching, the inadequate infrastructure, and the erratic and opaque assessment system.

These anomalies and many more are visible symptoms of much deeper and complex paradoxes. The inability of our system to be responsive towards a rather massive number of students, at the same time keeping up with the relentless pace of technological growth, coupled with the paucity of resources to sustain this growth are some reasons for the crises. Further are the contradictions involved in implementing the policies, political pressure, and an insensitive, inflexible bureaucratic state.

\section{The Widening Crevice of Irrelevance}

The alienation of higher education from the society they are supposed to work for brings in a sense of irrelevance to its cause (Chitnis 1997). While the population of India is overwhelmingly rural, most universities are located at urban centers. Thus, while the villages have remained wanting of skilled resources and developmental research, the cities are overcrowded by educated unemployed ignorant and insensitive to rural ethos. A similar case can be made about the scheduled caste and scheduled tribal populations who are not appropriately represented in the university system, and thus, there exists a significant lacuna in a comprehensive understanding of their ethos. This irrelevance becomes starker when new ideas and techniques are implemented. Since the planners are the products of this biased system, the new changes are more often than not beneficial to those already privileged. Even those responsible for designing courses for grassroots level development are completely distanced from and out of touch with life and work of the masses (Chitnis 1997). As a consequence, it leads to a dependence on civil society participation like non-governmental organizations to actually work for the emancipation for the working classes.

\section{The Ideological Dilemma of Language}

The issue of language has always been bridled with controversy in India. Since the British brought in universities in their native language, English has remained as a status symbol. The overemphasis on English often leads to a decline in the quality of education in the country. Moreover, the idea of shifting towards or including regional languages has not been easy either. The lack of literature and publications available in non-English Indian languages make it very convenient at the level of higher education. There are also concerns of the imposition of Hindi on other regional languages, as well as a lack of political will and firm leadership.

\section{Education and Development}

There is an assumption, shared even by bodies like the World Bank, that the expansion of education will lead to more jobs and better opportunities. Thus, increasing enrolment in higher education is a major requirement to develop an economy. However, the contrary has seemed to be true in cases like that of India where at this stage now, the expansion has to be curbed because of its inefficacy. It is rather pertinent to note here that the expansion of higher education will lead to economic growth only if, and when, this expansion substantively provides for the knowledge, skills, and attitudes that are needed. The gap between what the system provides and what the country needs need to be reevaluated. 


\section{Vested Interests of Politics}

Having discovered that the establishment of a college brings prestige, power, and popularity, politicians look at the higher education sector as one of the surest means of securing the support of an electorate. One of the major supports of Indian Higher Education is the State, understandably since the efforts by the State are necessary to mobilize the masses to join Higher Education. However, government funding comes with many controls and with an extensive bureaucratization of practices and procedures. It is also unfortunately accompanied by political pressures and interference. These hurdles, unfortunately, have led to an outflow of those willing to provide a responsive quality education and been replaced by those who either desire for political power or commercial interests. The regulatory bodies, like the University Grants Commission, function more as administrators and provide negligible resistance to such vested interests.

\section{Participation of Non-government Bodies}

Non-government institutions in India were started by the missionaries in the pre-independence era who considered it to be an instrument for the promotion of their religious philosophy and values. They were joined by caste and community organizations interested in providing opportunities for their youth, and by socially committed citizens and idealists. However, after liberalization in the 1990s, a new breed of educators came into the picture who understood the inability of the public sector to meet the demand alone and saw higher education as a lucrative business (Tilak, 2018). Thus, although the country continues professing an ethos of a not-for-profit education sector, the values on the ground have shifted from social welfare to individual gains. The aforementioned vested interests have further resulted in market-friendly policies to support the establishment of private institutions that run based on entrepreneurial motives rather than academic ones (Chattopadhyay, 2009). As a result, the issues of access, quality, and equity are increasingly becoming redundant as they are not relevant for the market.

\section{Impact of Research}

Unsatisfactory quality of research is an element that comes in all studies done on Indian academia. Tilak (2018) and Patel (2017) state that most higher education institutions are still geared towards teaching. Further, most research is done as an obligation for career advancement (Srivastava 2017). Since academic rigor is not given its due importance, the research ecosystem finds itself with poor fund allocation, managerial and administrative constraints of institutions, and negligence of social science and humanities (Singh 2015). The dominance of English also does not help the cause as the language deficit leads to many not being able to publish their work in good journals. The above factors lead to a number of researchers willing to publish in obscure journals to gain the required points rather than striving to research. The dominance of the Western academic hegemony where a certain set of paradigms, methodologies, and values suitable only to the West furthers the mediocrity of research. 


\section{Cultural Hegemony over the University}

In the West, or more particularly most of Europe and North America, universities, although elite and distanced from the masses, have their roots into the life of the people and have been free to advance. In contrast, universities in developing societies were planted as alien institutions by colonial rulers, to serve the limited needs of their commerce and governance. Most of these countries, including India, are still ingrained with the same system. There is an emphasis on absorbing knowledge, without attention to building knowledge and to advancing its applications. There is very little concern for developing capabilities for critical analysis, creative thinking, experimentation, and exploration. Till independence, there were minimal institutions for post-graduation and practically none for research. The IITs and IIMs were built as a consequence, but the efforts have not yet been firm or extensive enough. Indians, including those studying in IITs and IIMs, continue to look up to universities in Europe and North America for advanced education. Thus, even though the present system is a manifold improvement on the one set by the British, it continues to be bereft of the "soil." Many changes sought continue to be spurious and superficial, ignoring cultural ethos.

\section{The Influence of Sociopolitics}

Universities do not function in isolation with the rest of society. Thus, it is also essential to understand the contemporary political dynamics in the country to understand some features in university campuses. The ideological influence of the incumbent government always has a significant effect on the course structure and demography of universities. At present, while some scholars opine that there are attempts to saffronize the campuses, others are of the opinion that they have challenged the long-existing left hegemony in campuses. Either way, this has led to a lot of resistance and unrest in many universities.

Indian higher education is subjected to very high-handed regulations-both at the Center and the State. Everything is controlled by them right from whom to appoint as faculty, what to teach and whom to admit. However, with the development of critical thinking and encouragement of free speech on campuses, students resort to activism in these matters. In fact, what makes social change possible is the ceaseless conflict, compromise and adjustment between different perspectives. Its history, as Gramsci would say, is filled with illustrations of dominant groups seeking to establish their "hegemony" over the whole society.

There have also been some recent amendments proposed about education in general and social science higher education in particular. There have been drastic changes in admission procedures, scholarships and faculty hiring, to name a few. The idea and selection of Institutions of Eminence, a liminal stature given to the University Grants Commission, the constantly changing list of journal recognition, the National Education Policy of 2019, and the Higher Education Commission of India Bill of 2019 are some instances of changes wrought for academia.

Higher education in India has grown phenomenally since independence, and today, India has over thirty-seven million students enrolled in higher education (AISHE 2019). Meanwhile, resources for higher education are continuously shrinking. Along with the current national political situation, the above events had been seeing a lot of student activism and unrest on the city streets, within campuses and online. Students were on the streets for 
a range of issues, from reduction or removal of scholarships to opposing the citizenship act of the country, deemed discriminatory by many.

In the midst of all this, a global public health crisis not only changed the direction of events; it also made everyone reevaluate our existing social institutions. Online education, till recently considered an aberration, or an alternative delivery method aimed primarily at a distinguished population of students, has moved aggressively into the mainstream of higher education, especially in the past few months due to the pandemic and the subsequent lockdown.

\section{Living with the Pandemic}

In India, like many parts of the world, there was an almost overnight shift to virtual classes in schools and universities when the government imposed a nationwide lockdown. As a result, online and virtual learning that had been a gradual and somewhat lackluster process until then suddenly became mainstream and necessary. Along with online classes, university students had to vacate their hostels, and either go back home or arrange alternate living conditions. While some universities did a smoother transition, a large number of students were left in a dire situation fending for themselves. The classes were expectedly not planned, given the short time between notification and implementation. This not only led to less than good education being imparted, but it can also be thought to take a step towards the furthering of existing inequalities in academia. Those who have access to infrastructure and the internet were able to transit comparatively smoothly, whereas others are out missing classes.

Since the process has started, there has been a lot of focus and preoccupation with the efficiency of technology, the mechanics to create the courses, and the logistics of dispensing the material. What is neglected in the whole discourse is that providing a conducive environment even while learning virtually is equally essential. Students from privileged backgrounds have not had a hard time adjusting to the changes, while others have not been as lucky. It is not hard to imagine that this differential experience will ultimately lead to increasing the bridge between those who can afford merit and legitimate knowledge and those who cannot. Further, the issues of adaptability of children with special needs and learning disabilities are not getting its due recognition.

The circumstances have also brought forth other pressing issues. The migrant crisis, and its mishandling, is a blot on the Indian scenario that will be seared into our consciousness for a long time. Several NGOs and citizens, including students and student groups, have been working untiringly at their individual capacities to help them out. In such a case, the pre-pandemic protests about university autonomy, academic freedom and other national concerns became a low priority. However, it does not imply that the protests and the unrest are over. Students, negotiating with their newfound ordeal, know that they are in it for the long run.

The issues have also been continually changing. At present, students are asked to submit assignments or take exams by their universities without even considering the varied difficulties faced by a number of them. Along with inaccessibility of laptop or Internet, familial problems are also commonplace with COVID-19 affecting indiscriminately. Insensitivity and inconsiderate behavior towards these issues are other underlying causes of dissent. These often turn into a lack of flexibility, which makes remaining enrolled increasingly tricky. The coming up of new grave issues does not mean all others are resolved. 


\section{Insights on the Road Ahead}

The year 2020 will be known for a lot. Undeniably, the middle months would be significant for the ongoing large-scale protests all over the world. Many countries like the USA and UK have seen citizens coming down on the streets, despite the pandemic situation, due to the seriousness of the cause. University students, while playing a significant role in these, have questioned the mainstream knowledge systems in their respective regions. India is no exception in this regard. The social, physical, and emotional toll of the times, thus, makes for a critical juncture in higher education globally.

Most countries are faced with similar problems of massive increase in the size of student populations, the contradictions in ideals of equality and social justice, and reaching of balance between coping with the phenomenal growth of knowledge and technology, and producing employable students. Nevertheless, the Indian experience suggests that in developing countries, the problems are far more complex. For, in addition to the issues they share with the developed countries, they also have to cope with a series of problems that are derived from their colonial legacy.

The Indian government, as a result, post-independence occasionally comes up with education policies to direct the future of the country's education. While the first one that released in 1968 resulted in being path-breaking for the education scenario for the whole country for a long time, and continues to be one of the most revered documents produced by the country in the field of education, the latter ones have been inferior imprints. The latest one-National Education Policy (NEP) 2020-has been released within the lockdown during the current pandemic. Although there have been questions about its democratic passage to being released, nevertheless, it offers a diagnosis of the challenges in the field of higher education and a vision for overhauling and re-energizing it. In various explicit terms and undertones, the policy hints at a centralized state control in the governance of education and restraining the political activism of students (Jayal 2020).

Since the implementation aspects in the document are wanting, there is no way to claim if and how the changes mentioned in the policy would actually translate into practice. It points out things like lack of access to higher education in socio-economically disadvantaged areas, and the lack of emphasis on research in colleges and universities. However, many proposed changes are manifestly meaningless. "moving towards faculty and institutional autonomy" and "reaffirming the integrity of faculty and institutional leadership positions through merit-appointments and career progression based on teaching, research, and service" to name a few (NEP 2020, 33-34). The core of the plan for the overhaul of higher education is its structural reorganization into large, multidisciplinary universities and colleges (at least one in or near every district), with many of these offering instruction in local languages. Nevertheless, as already stated, there is no clarity on how this would happen. There is also the proposal of creating "vibrant multidisciplinary environments," and as harbingers of a fundamental change in the "conceptual perception/understanding of what constitutes a higher education institution" (NEP 2020, 34). On the whole, the recommendations are less about fixing the problems in existing institutions and repurposing them; they are more in the nature of reimagining the entire system (Jayal 2020). On the other hand, many structural problems that plague higher education are altogether ignored. For instance, the massive faculty shortage and reliance on ad hoc and guest faculty, and the exploitative conditions in private colleges find no mention. It does not take much imagination to estimate the impact of these working conditions on the quality of education (Kuhad 2020). 
Higher education institutions cannot afford to remain isolated and pursue issues without any heed to the sociocultural context in which they are embedded and get nurturance. The pandemic has exposed many features of our society that cannot be ignored anymore. How higher education is planned and targeted now is going to be critical as to which students will it cater to. It is imperative not to lose all the learning that these uncertain times are teaching us about humanity and vulnerability.

\section{References}

Altbach, P. G. (1974). University crisis in India. Change: The Magazine of Higher Learning, 6(3), 20-21.

Beteille, A. (2005). Universities as public institutions. Economic and Political Weekly, 40(31), 3377-3381.

Beteille, A. (2010). Universities at the Crossroads. Delhi: Oxford University Press.

Chandra, P. (2017). Building universities that matter: Where are Indian institutions going wrong? New Delhi: Orient BlackSwan.

Chattopadhyay, S. (2009). The market in higher education: Concern for equity and quality. In JBG Tilak (Ed.), Higher Education in India: In Search of Equality, Quality and Quantity. New Delhi: Orient Black Swan.

Chitnis, S. (1997) I.P. Desai Memorial Lecture: The Crisis in Higher Education. Surat: Centre For Social Studies.

Deshpande, S. (2009). Inclusion versus excellence: Caste and the framing of fair access in Indian higher education. South African Review of Sociology, 40(1), 127-147.

Guha, R. (2007). Pluralism in the Indian University. Economic and Political Weekly, 42(7), 564-570.

Gundemeda, N. (2017). The idea of a university: A sociological study of a national university in India. Journal of Sociology and Social Anthropology, 6(1), 99-112.

Jayal, N.G. (2020). NEP 2020 on Higher Education. Retrieved from https://www.theindiaforum.in/article/nep2020-higher-education.

Kuhad, R. C., \& Kumar, S. (2020). Reimagining Indian higher education through new national education policy. University News, 58(33), 35-39.

Ministry of Human Resource Development. (2019). All India survey on higher education. New Delhi: Department of Higher Education, MHRD.

Ministry of Human Resource Development. (2020). National Education Policy 2020. New Delhi: MHRD.

Ministry of Human Resource Development. (2020). National Education Policy (NEP). New Delhi: MHRD.

Misra, G., \& Mishra, R. (2018). New India- universities in the middle of economic development. In J. Valsiner, A. Lutsenko, \& A. A. Antoniouk (Eds.), Sustainable Futures for Higher Education: Cultivating Knowledge Makers. $\mathrm{CH}$ : Springer.

Misra, G., Mishra, R., \& Misra, I. (2020). Higher education in India: some perspectives for reimagining the universities. University News, 58(33), 28-34.

Naik, J. P. (1965). Educational Planning India. New Delhi: Allied Publishers.

Patel, P. J. (2017). Research culture in Indian universities: The debate continues. Social Change, 47(1), 94-100.

Rizvi, F. (2012). Challenges in higher education. In P. Agarwal (Ed.), A Half-century of Indian higher education. New Delhi: SAGE.

Singh, R. (2015). Indian higher education and research ecosystem: Directions to a world class knowledge nation. In H. Chaturvedi (Ed.), Transforming Indian Higher Education. New Delhi: Bloomsbury Publishing.

Srivastava, V. K. (2017). The state of research culture in Indian universities. Social Change, 47(1), 101-107.

The International Bank for Reconstruction and Development. (1994). Higher Education: The Lessons of Experience - Development in Practice Series. Washington DC: The World Bank.

Tilak, J. B. G. (2018). On planning university development: Shibboleths versus stylized facts? Social Change, $48(1), 1-24$.

Urvashi, S. (2018). Student political movement in India. Indian Journal of Dalit and Tribal Studies and Action, $3(3), 22-31$.

Viswanathan, S. (2000). Democracy, plurality and Indian University. Economic and Political Weekly, 35(40), 3597-3606.

Publisher's Note Springer Nature remains neutral with regard to jurisdictional claims in published maps and institutional affiliations. 